\title{
The Effect of Denosumab on Bone Mass in Super Elderly Patients
}

\author{
Chaiho Jeong, Jeonghoon $\mathrm{Ha}$ \\ Division of Endocrinology and Metabolism, Department of Internal Medicine, Seoul St. Mary's Hospital, College of Medicine, The Catholic \\ University of Korea, Seoul, Korea
}

Corresponding author

\section{Jeonghoon $\mathrm{Ha}$}

Division of Endocrinology and Metabolism, Department of Internal Medicine, Seoul St. Mary's Hospital, College of Medicine, The Catholic University of Korea,

222 Banpo-daero, Seocho-gu, Seoul 06591, Korea

Tel: +82-2-2258-6372

Fax: +82-2-599-3589

E-mail: hajhoon@catholic.ac.kr

Received: February 13, 2020

Revised: April 21, 2020

Accepted: April 29, 2020
Background: Denosumab is a potent antiresorptive drug leading to significant reduction in the risk of vertebral and non-vertebral fractures in postmenopausal osteoporosis. The effect of denosumab in super-elderly patients lacks data to date and few literature has proven the efficacy to this specific group. The purpose of this study was to determine the effectiveness and safety of denosumab in the super-elderly. Methods: We retrospectively evaluated 60 patients older than 80 with osteoporosis treated with denosumab. Patients were treated with denosumab every 6 months for 12 months 2017 to 2020. The primary endpoint was defined by the changes in bone mineral density (BMD) of 3 measurement sites: the lumbar spine, femoral neck, and total hip. Changes in bone turnover markers, serum calcium, serum phosphate, and 25-hydroxy-vitamin D were

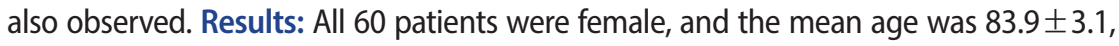
from age 80 to 94 . After 12 months of denosumab treatment, significant increases in BMD were observed; $3.02 \pm 2.74 \%$ for the lumbar spine $(P=0.000), 3.10 \pm 6.90 \%$ for the femoral neck ( $P=0.005)$, and $2.89 \pm 5.80 \%$ for the total hip ( $P=0.002)$ The bone turnover marker $\mathrm{C}$-terminal telopeptide of type I collagen and osteocalcin significantly declined after 12 months of treatment $(-34.8 \pm 45.9 \% ; P=0.002$ and $-35.5 \pm 38.9 \% ; P=0.004$ respectively). Symptomatic hypocalcemia and serious adverse drug reactions that required drug discontinuation were not observed during treatment. Conclusions: Denosumab is thought to be an anti-osteoporotic medication that is sufficiently effective and safe even for the super-elderly.

Key Words: Aged · Bone density · Denosumab · Osteoporosis

\section{INTRODUCTION}

Between 2019 and 2050, the number of persons' age 65 or older globally is expected to more than double. The number of people older than age 80 is growing even faster than the number of people older than age 65 and it is expected to nearly triple to 426 million in 2050 globally.[1] As a consequence of aging, the incidence of osteoporosis and prevalence of osteoporotic fractures are increasing dramatically.[2] The 10-year probability of major osteoporotic fractures rises with age and is especially high in patients older than 75.[3,4] The prevalence of vertebral fractures among people older than age 80 exceeds 50\%.[5] Furthermore in the elderly, the costs and morbidity associated with osteoporotic fractures are considerable, especially for hip fractures.[6,7] After hip fractures, approximately
Copyright $(\odot 2020$ The Korean Society for Bone and Mineral Research

This is an Open Access article distributed under the term of the Creative Commons Attribution Non-Commercial License (https://creativecommons.org/licenses/by-nc/4.0/ which permits unrestricted non-commercial use, distribution, and reproduction in any medium, provided the origina work is properly cited.

\section{KSBMR}


$20 \%$ of patients do not survive the next year and $50 \%$ do not regain their previous level of ability.[8]

Fracture risk can be prevented with anti-osteoporotic therapy, thereby reducing mortality risk in elderly females and possibly males.[2,9] Denosumab, the first approved biologic agent for the treatment of osteoporosis is a potent antiresorptive drug leading to significant reduction in the risk for hip, vertebral, and non-vertebral fractures in postmenopausal osteoporosis.[10] Furthermore, denosumab has a high persistence and adherence in postmenopausal females with osteoporosis.[11] Several guidelines recommended denosumab as the first line of treatment for patients with osteoporosis without fractures and with severe osteoporosis with fractures.[12,13] In the elderly, several factors, such as frailty and reduced homoeostasis increase the complexity of management of drugs, and drugs side effects often occur in the elderly.[14] Since data on the efficacy and safety of denosumab use in the super-elderly (age 80 years or older) are not sufficient to conclude. Thus, we intend to confirm the clinical utility of denosum$a b$ in the super-elderly patients.

\section{METHODS}

We retrospectively evaluated 60 patients with osteoporosis more than 80 years old who were treated with denosumab. Patients were treated with denosumab every 6 months for 12 months between the years 2017 and 2020 in a single tertiary center. The bone mineral densities (BMDs) of the lumbar spine, femoral neck, and total hip were measured in grams per square centimeter using dual energy $X$ ray absorptiometry (DXA; Lunar Prodigy Advance; GE Lunar, Madison, WI, USA). The coefficient of variation was $1.0 \%$ for the lumbar spine, $1.5 \%$ for the femoral neck, and $0.9 \%$ for the total hip. The institutional least significant change with $95 \%$ confidence interval is $0.042 \mathrm{~g} / \mathrm{cm}^{2}$. Patients underwent DXA every 12-month interval after the first administration of denosumab. Most of participants were under supplementation of oral vitamin $D$ and calcium. Blood samples were taken after overnight fasting, biochemical tests like serum C-terminal telopeptide of type I collagen (CTX), serum 25-hydroxy (25[OH]) vitamin, serum calcium and phosphate were checked before denosumab therapy and every 6-month interval after denosumab treatment until the end of final injection. This study was approved by the Institutional Review Board (KC19RISI0846).

\section{Statistical analysis}

Continuous variables were expressed as mean \pm standard deviation or percentage unless otherwise stated. Categorical variables were described based on relative frequencies. For comparison, paired $t$-test was used in continuous variables with normal distribution. The Wilcoxon signed rank test was used to evaluate the differences between variables in cases in which the distributions were not normally distributed. A 2-tailed $P$-value of less than 0.05 was considered as statistically significant. All statistical analyses were performed using IBM SPSS Statistics for Windows version 24.0 (IBM Corp., Armonk, NY, USA)

\section{RESULTS}

The baseline characteristics of patients before denosumab treatment are summarized in Table 1. All 60 were female patients, the mean age was $83.9 \pm 3.1$, age 80 to 94 . Four patients were age 90 or older. Baseline bone turnover markers were $0.36 \pm 0.28 \mathrm{ng} / \mathrm{mL}$ for CTX and $17.8 \pm 10.3 \mathrm{ng} / \mathrm{mL}$ for osteocalcin. The 44 (73.3\%) patients had undergone prior treatment before denosumab therapy for osteoporosis, mostly bisphosphonate (BP; 41.7\%). The 17 (28.3\%) of the patients experienced a fracture in at least one skeletal site. All patients had calcium or vitamin D supplementation, which led to a serum $25(\mathrm{OH})$ vitamin D of $33.9 \pm 9.8 \mathrm{ng} / \mathrm{mL}$.

After 12 months of denosumab treatment, significant increases in BMD were observed in all measurement sites compared to the baseline $(3.02 \pm 2.74 \%$ for the lumbar spine $[P=0.000], 3.10 \pm 6.90 \%$ for the femoral neck $[P=0.005]$, and $2.89 \pm 5.80 \%$ for the total hip $[P=0.002])$. In subgroup analysis, denosumab also showed a significant BMD increase in patients more than 85 years old in all measurement sites compared to the baseline $(3.17 \pm 3.36 \%$ for the lumbar spine $[P=0.009], 2.69 \pm 5.50 \%$ for the femoral neck $[P=0.024]$, and $2.61 \pm 5.63 \%$ for the total hip $[P=0.030]$ ) (Fig. 1). A greater increase in $B M D$ in all sites were demonstrated in drug naïve patients compared to those in patients with prior osteoporosis treatment (Fig. 2).The bone turnover marker CTX and osteocalcin significantly declined after 12 months of treatment $(-34.8 \pm 45.9 \% ; P=0.002$ and $-35.5 \pm 38.9 \%$; $P=0.004$ respectively) (Table 2). No serious symptomatic hypocalcemia $(<8 \mathrm{mg} / \mathrm{dL}$ ) was noted. The vitamin D level 
was maintained at recommended level $(37.4 \pm 13.7 \mathrm{mg} / \mathrm{dL}$ at 12 months). Serious adverse drug reactions that required drug discontinuation were not reported.

Table 1. Baseline clinical characteristics of study population $(n=60)$

\begin{tabular}{|c|c|}
\hline Variables & Value \\
\hline Age (yr) & $83.9 \pm 3.1$ \\
\hline \multicolumn{2}{|l|}{ Age } \\
\hline $80 \leq$ age $<85$ & $40(66.7)$ \\
\hline $85 \leq$ age $<90$ & $16(26.7)$ \\
\hline$\geq 90$ & $4(6.6)$ \\
\hline $\mathrm{BMI}\left(\mathrm{kg} / \mathrm{m}^{2}\right)$ & $22.8 \pm 3.1$ \\
\hline $\begin{array}{l}\text { Cross-linked C-terminal telopeptide of type } \\
1 \text { collagen }(\mathrm{ng} / \mathrm{mL})\end{array}$ & $0.36 \pm 0.28$ \\
\hline Osteocalcin (ng/mL) & $17.8 \pm 10.3$ \\
\hline Serum GFR $\left(\mathrm{mL} / \mathrm{min} / 1.73 \mathrm{~m}^{2}\right)$ & $70.5 \pm 21.1$ \\
\hline Serum Ca (mg/dL) & $9.0 \pm 0.4$ \\
\hline Serum $P(m g / d L)$ & $3.4 \pm 0.6$ \\
\hline 25(OH)D (ng/mL) & $33.9 \pm 9.8$ \\
\hline \multicolumn{2}{|l|}{ Baseline BMD $\left(\mathrm{g} / \mathrm{cm}^{2}\right)$} \\
\hline L-spine & $0.851 \pm 0.140$ \\
\hline Femur neck & $0.644 \pm 0.078$ \\
\hline Total hip & $0.684 \pm 0.095$ \\
\hline Previous fracture history & $17(28.3)$ \\
\hline \multicolumn{2}{|l|}{ Prior treatment of osteoporosis } \\
\hline None & $16(26.7)$ \\
\hline Bisphosphonate & $25(41.7)$ \\
\hline PTH analogue & $11(18.3)$ \\
\hline SERM & $8(13.3)$ \\
\hline \multicolumn{2}{|l|}{ Prescription of other medications } \\
\hline Calcium and vitamin D & $60(100.0)$ \\
\hline Anti-diabetic agent & $12(20.0)$ \\
\hline Thyroid hormone replacement & $8(13.3)$ \\
\hline Steroid & $7(11.7)$ \\
\hline
\end{tabular}

The data is presented as mean \pm standard deviation or number (\%). $\mathrm{BMI}$, body mass index; GFR, glomerular filtration rate; Ca, calcium; $\mathrm{P}$, phosphorous; $25(\mathrm{OH}) \mathrm{D}$, 25-hydroxy-vitamin $\mathrm{D}$; BMD, bone mineral density; $\mathrm{PTH}$, parathyroid hormone; SERM, selective estrogen receptor modulator.

\section{DISCUSSION}

In this retrospective study, we analyzed the results of denosumab therapy in patients mean age $83.9 \pm 3.1$, and denosumab effectively increased bone mass in the elderly

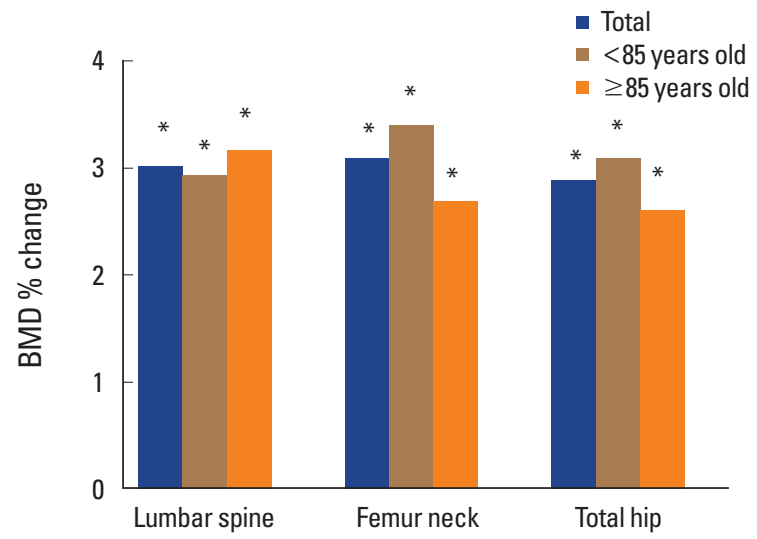

Fig. 1. The percentage change of bone mineral density (BMD) after one year of denosumab treatment. ${ }^{*} P<0.05$ compared with the baseline.

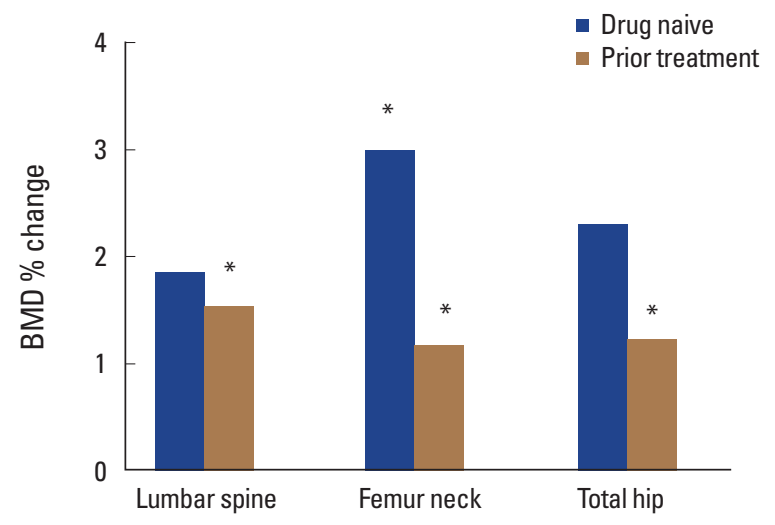

Fig. 2. The percentage change of bone mineral density (BMD) after one year of denosumab treatment between group with prior osteoporosis medication and group without prior osteoporosis medication. ${ }^{*} P<0.05$ compared with the baseline.

Table 2. Changes in biochemical markers after one year of denosumab

\begin{tabular}{lccccc}
\hline & Baseline & 6 months & 12 months & Percentage change $(\%)^{\text {a) }}$ & $P$-value \\
\hline CTX $(\mathrm{ng} / \mathrm{mL})$ & $0.36 \pm 0.28$ & $0.19 \pm 0.13$ & $0.18 \pm 0.10$ & $-34.8 \pm 45.9$ & 0.002 \\
Osteocalcin (ng/mL) & $17.8 \pm 10.3$ & $8.4 \pm 3.2$ & $9.7 \pm 5.0$ & $-35.5 \pm 38.9$ & 0.004 \\
25(OH)D (ng/mL) & $33.9 \pm 9.8$ & $36.2 \pm 12.6$ & $37.4 \pm 13.7$ & $20.9 \pm 46.4$ & 0.107 \\
Calcium (mg/dL) & $9.0 \pm 0.4$ & $9.1 \pm 0.5$ & $9.1 \pm 0.3$ & $0.5 \pm 3.4$ & 0.399 \\
Phosphorous (mg/dL) & $3.4 \pm 0.6$ & $3.3 \pm 0.5$ & $3.4 \pm 0.4$ & $0.3 \pm 15.3$ & 0.844 \\
\hline
\end{tabular}

alPercentage change of baseline vs. 12 months.

CTX, C-terminal telopeptide of type I collagen; 25(OH)D, 25-hydroxy-vitamin D. 
patients. Significant increases in BMD were also observed after denosumab administration, even if previously treated with other anti-osteoporotic medications, especially in those under 85 years of age. Even in patients older than 85 years, denosumab was found to be effective and safe.

Osteoporosis is a major clinical problem in the elderly. Bone loss continues throughout life for older males and females $[15,16]$ and almost any bone can fracture as a result of the bone fragility of osteoporosis. Since the prevalence of osteoporotic fracture increases with age, management to prevent osteoporosis and its fractures are of a major health concern.[17] Denosumab is an effective treatment to prevent vertebral and hip fractures in the elderly.[18,19] Furthermore, considering that osteoporosis also bears economic burden to the elderly, cost effectiveness of denosumab compared to BPs in postmenopausal osteoporotic females as well as in elderly osteoporotic males [20-22] is also an advantage. Besides, denosumab pharmacokinetics are not expected to be affected by hepatic impairment or by decreased renal function, making it a better treatment option for the vulnerable elderly.[23]

Although our data (mean age, 83.9 \pm 3.1 ) showed that BMD increased significantly in all skeletal sites, the increase was lower than that observed in data from the Fracture Reduction Evaluation of Denosumab in Osteoporosis Every 6 Months (FREEDOM) trial which demonstrated the effect of denosumab in a group of population mean age $72.3 \pm$ 5.2.[10] Aging is associated with the reduction in bone formation since the proportion of osteoblast undergoing apoptosis increases with aging.[24,25] As a consequence, the reduction in trabecular volume, number, and width have been well demonstrated in specimens of older bones as well as cortical bones.[26,27] A reciprocal increase in bone marrow adiposity is also another reason for the reduction in the trabecular bone with aging.[28] Additionally, previous studies have suggested that the change of drug metabolism with aging may have affected the action of denosumab.[29] Elderly patients are at high risk of drug interactions. They frequently take several drugs, have many co-morbidities, and may not maintain appropriate nutritional status. [30] Age-related pharmacokinetic and pharmacodynamic changes $[31,32]$ can potentially increase the risk of adverse events from drug interactions. Despite the limitations of these drug responses in elderly patients, denosumab has been shown to have significant effects in this patient group.
There are several limitations in this study. First, we mainly focused on BMD rather than focusing on fracture risk. Aging is associated with reduced bone mass as well as reduced quality of bone. Thus, older patients are more susceptible to fractures than younger patients with the same BMD. $[33,34]$ Future studies are needed to evaluate the effect of denosumab on the fracture risk of very elderly patients. Second, we did not consider the multi drug interaction of the elderly. Older patients are likely to have multiple chronic disease making polypharmacy more prevalent.[35] Although drug interaction in the elderly is uncertain and the interaction with anti-osteoporotic medication was not verified, it could have affected the efficacy of denosumab in this group of the population. Third, the small number of sample in our study and the short observation period is another limitation. A study with greater population may show a more significant information about denosumab treatment in the super-elderly.

Osteoporotic fracture is associated with higher health care costs, physical disability, impaired quality of life, and increased mortality, especially for the super-elderly. In considering the treatment of osteoporosis in the super-elderly, physicians must consider the efficacy as well as the safety and compliance of each therapeutic agent. Denosumab is a safe as well as effective treatment for osteoporosis in the super-elderly with good compliance.

\section{DECLARATIONS}

\section{Ethics approval and consent to participate}

This study was approved by the Institutional Review Board of Seoul St. Mary's Hospital, the Catholic University of Korea (KC19RISI0846).

\section{Conflict of interest}

No potential conflict of interest relevant to this article was reported.

\section{ORCID}

Chaiho Jeong https://orcid.org/0000-0002-2914-2278

Jeonghoon $\mathrm{Ha}$ https://orcid.org/0000-0001-9219-7135

\section{REFERENCES}

1. United Nations, Department of Economic and Social Af- 
fairs, Population Division. World population prospects 2019: Highlights (ST/ESA/SER.A/423). 2019 [cited by 2020 Jan 3]. Available from: https://population.un.org/wpp/ Publications/Files/WPP2019_Highlights.pdf

2. Ettinger MP. Aging bone and osteoporosis: strategies for preventing fractures in the elderly. Arch Intern Med 2003; 163:2237-46

3. Kanis JA, Johnell O, Oden A, et al. Ten year probabilities of osteoporotic fractures according to BMD and diagnostic thresholds. Osteoporos Int 2001;12:989-95.

4. Ström O, Borgstrom F, Kanis JA, et al. Osteoporosis: burden, health care provision and opportunities in the EU: a report prepared in collaboration with the International Osteoporosis Foundation (IOF) and the European Federation of Pharmaceutical Industry Associations (EFPIA). Arch Osteoporos 2011;6:59-155.

5. Wilkins $\mathrm{CH}$, Birge SJ. Prevention of osteoporotic fractures in the elderly. Am J Med 2005;118:1190-5.

6. Ray NF, Chan JK, Thamer M, et al. Medical expenditures for the treatment of osteoporotic fractures in the United States in 1995: report from the National Osteoporosis Foundation. J Bone Miner Res 1997;12:24-35.

7. Birge SJ, Morrow-Howell N, Proctor EK. Hip fracture. Clin Geriatr Med 1994;10:589-609.

8. Chrischilles EA, Butler CD, Davis CS, et al. A model of lifetime osteoporosis impact. Arch Intern Med 1991;151:202632.

9. Center JR, Bliuc D, Nguyen ND, et al. Osteoporosis medication and reduced mortality risk in elderly women and men. J Clin Endocrinol Metab 2011;96:1006-14.

10. Cummings SR, San Martin J, McClung MR, et al. Denosumab for prevention of fractures in postmenopausal women with osteoporosis. N Engl J Med 2009;361:756-65.

11. Petranova T, Boyanov M, Shinkov A, et al. Medication-taking behaviour in Bulgarian women with postmenopausal osteoporosis treated with denosumab or monthly oral bisphosphonates. Arch Osteoporos 2017;13:1.

12. Watts NB, Bilezikian JP, Camacho PM, et al. American association of clinical endocrinologists medical guidelines for clinical practice for the diagnosis and treatment of postmenopausal osteoporosis: executive summary of recommendations. Endocr Pract 2010;16:1016-9.

13. Khan SN, Craig L, Wild R. Osteoporosis: therapeutic guidelines. Guidelines for practice management of osteoporosis. Clin Obstet Gynecol 2013;56:694-702.
14. Gurwitz JH, Field TS, Harrold LR, et al. Incidence and preventability of adverse drug events among older persons in the ambulatory setting. JAMA 2003;289:1107-16.

15. Orwoll ES, Oviatt SK, McClung MR, et al. The rate of bone mineral loss in normal men and the effects of calcium and cholecalciferol supplementation. Ann Intern Med 1990; 112:29-34.

16. Hannan MT, Felson DT, Anderson JJ. Bone mineral density in elderly men and women: results from the Framingham osteoporosis study. J Bone Miner Res 1992;7:547-53.

17. Solomon DH, Finkelstein JS, Katz JN, et al. Underuse of osteoporosis medications in elderly patients with fractures. Am J Med 2003;115:398-400.

18. Boonen S, Adachi JD, Man Z, et al. Treatment with denosumab reduces the incidence of new vertebral and hip fractures in postmenopausal women at high risk. J Clin Endocrinol Metab 2011;96:1727-36.

19. McClung MR, Boonen S, Törring O, et al. Effect of denosumab treatment on the risk of fractures in subgroups of women with postmenopausal osteoporosis. J Bone Miner Res 2012;27:211-8.

20. Jönsson B, Strom O, Eisman JA, et al. Cost-effectiveness of denosumab for the treatment of postmenopausal osteoporosis. Osteoporos Int 2011;22:967-82.

21. Parthan $A$, Kruse $M$, Yurgin N, et al. Cost effectiveness of denosumab versus oral bisphosphonates for postmenopausal osteoporosis in the US. Appl Health Econ Health Policy 2013;11:485-97.

22. Silverman S, Agodoa I, Kruse M, et al. Denosumab for elderly men with osteoporosis: A cost-effectiveness analysis from the US payer perspective. J Osteoporos 2015;2015: 627631.

23. Wilcock A, Charlesworth S, Toller CS, et al. Denosumab: AHFS 92:24. J Pain Symptom Manage 2018;56:295-301.

24. Noble BS, Stevens $\mathrm{H}$, Loveridge $\mathrm{N}$, et al. Identification of apoptotic changes in osteocytes in normal and pathological human bone. Bone 1997;20:273-82.

25. Jilka RL, Weinstein RS, Bellido T, et al. Increased bone formation by prevention of osteoblast apoptosis with parathyroid hormone. J Clin Invest 1999;104:439-46.

26. Bergot C, Laval-Jeantet AM, Prêteux F, et al. Measurement of anisotropic vertebral trabecular bone loss during aging by quantitative image analysis. Calcif Tissue Int 1988;43: 143-9.

27. McCalden RW, McGeough JA, Barker MB, et al. Age-relat- 
ed changes in the tensile properties of cortical bone. The relative importance of changes in porosity, mineralization, and microstructure. J Bone Joint Surg Am 1993;75:1193205.

28. Rozman C, Feliu E, Berga L, et al. Age-related variations of fat tissue fraction in normal human bone marrow depend both on size and number of adipocytes: a stereological study. Exp Hematol 1989;17:34-7.

29. Turnheim K. When drug therapy gets old: pharmacokinetics and pharmacodynamics in the elderly. Exp Gerontol 2003;38:843-53.

30. Mallet $L$, Spinewine A, Huang A. The challenge of managing drug interactions in elderly people. Lancet 2007;370: 185-91.

31. Cusack BJ. Pharmacokinetics in older persons. Am J Geri- atr Pharmacother 2004;2:274-302.

32. Mangoni AA, Jackson SH. Age-related changes in pharmacokinetics and pharmacodynamics: basic principles and practical applications. Br J Clin Pharmacol 2004;57:614.

33. Hui SL, Slemenda CW, Johnston CC, Jr. Age and bone mass as predictors of fracture in a prospective study. J Clin Invest 1988;81:1804-9.

34. De Laet $\mathrm{CE}$, van Hout $\mathrm{BA}$, Burger $\mathrm{H}$, et al. Bone density and risk of hip fracture in men and women: cross sectional analysis. BMJ 1997;315:221-5.

35. Maher RL, Hanlon J, Hajjar ER. Clinical consequences of polypharmacy in elderly. Expert Opin Drug Saf 2014;13: 57-65. 